\title{
Spray characteristics of biofuel-gasoline blends through an asymmetric multi-hole injector of DISI engines
}

\author{
Ling Shi ${ }^{1, a^{*}}$, Qianwang Fan ${ }^{2, b}$ \\ ${ }^{1}$ Tianhua Colleges, Shanghai Normal University,Chinese \\ ${ }^{2}$ Beijing Automotive Technology Center,Chinese \\ ashiling821@126.com, bfanqianwang@126.com
}

\begin{abstract}
Keywords: Spray Characteristics, Multi-hole Injector, Optical Chamber, Biofuel
Abstract. Biofuel is an attracted alternative fuel. While biofuel-gasoline blends are used for substituting some part of gasoline, and to some extent it is favorable to direct injection homogeneous charge combustion ignition (DI-HCCI) engine application, improving auto-ignition ability and reducing high-pressure pump friction. In this study, the spray characteristics of various blends of the biofuel and gasoline $(10 \%, 20 \%$ and $30 \%$ biofuel made from edible waste oil) as well as pure gasoline were investigated by means of high-speed shadow photography technique, employing a multi-hole DISI engine injector with asymmetrical nozzle-hole arrangement. A comparative analysis of spray characteristics of biofuel-gasoline blends and pure gasoline was presented as well. Such the parameters as spray tip penetration, spray cone angle, spray tip speed and spray projection area were calculated by means of the spray images. The results showed that the initial spray pattern of the blends with different biofuel fraction in the gasoline is distinct. The spray tip penetration and the spray tip speed increased with the increase in biofuel volume fraction, due mainly to an increase in fuel viscosity preventing the breakup of the spray jet, resulting in an increase in the size of the spray droplets. In addition, Regardless of the biofuel fraction in the gasoline, the spray fuel concentrations were richer and richer with the increase in the injection pressure, due to increasing the fuel injection rate.
\end{abstract}

\section{Introduction}

Direct Injection Spark Ignition (DISI) engines have a potential to remarkably reduce the fuel consumption and enhance the engine performance [1]. Therefore, over the past two decades, the DISI engine has been greatly evolved, and various types of DISI productions have been put into the market. For a DISI engine, the detailed characteristics the spray that is injected directly into the combustion chamber are paramount importance to the combustion efficiency and the resultant engine-out emissions. And whether the injected fuel can be atomized in a very short time will greatly affect the whole combustion process and engine performance. To study the spray characteristics of a gasoline direct injection (GDI) injector, a lot of investigations have been achieved by experiments and CFD simulations as follows.

Gao. J. et al [2] investigated the spray characteristics of different blends of ethanol-gasoline (25\%, $50 \%, 75 \%$ and $100 \%$ ) as well as pure gasoline under various ambient conditions by means of high-speed schlieren photography technique. The results showed that when adopting fuel blends with variable ethanol-gasoline fractions in the swirl-type injector sprays, the spray developing patterns were not significantly changed.

Zhang X S et al [3] studied the spray characteristics of bio-diesel employing high-speed camera at an atmospheric condition in a diesel pump test-bed. The results showed that the general behavior in spray characteristics of bio-diesel was similar to that of diesel. However, bio-diesel gave longer spray penetration distance and half spray angle comparing with those of diesel.

Shiraishi T. et al [4] investigated the effect of spray characteristics on combustion with a side direct injection gasoline engine and flat piston. The results showed that the fuel spray, which has lower fuel pressure, lower penetration and wider spray angle, was disturbed to disperse into the cylinder by the intake air flow. In addition, the mixture distribution was put aside in the cylinder. 
Lee K.H et al [5] studied the characteristics of a direct injection gasoline spray by using entropy analysis and PIV methods. The results showed that the viscous friction due to velocity gradient was less dominant than the evaporation at the downstream of spray by comparing entropy analysis and vorticity strength.

Keiya N. [6] investigated spray characteristics and the mixture formation process of sprays injected from two-hole nozzles for direct-injection spark-ignition (DISI) engines using the laser absorption scattering (LAS) technique and the computational fluid dynamics (CFD) simulation. The results showed that as the hole-axis-angle (HAA) of the two-hole nozzle decreased, the droplet coalescence increased and vapor mass decreased.

Aleiferis P.G. [7] investigated the spray formation and combustion characteristics of gasoline and E85, employing a multi-hole injector with asymmetric nozzle hole arrangement, by high-speed imaging and droplet sizing in a quiescent chamber and in an optical DISI engine. The results showed E85 spray formation was more insensitive to changes in temperature and pressure when in combination compared to gasoline.

A lot of investigations have been conducted for studying the spray characteristics of a GDI injector. However, a few spray characteristics of biofuel-gasoline blends have been studied so far. The study mainly focused on the spray characteristics and spray cloud concentration of biofuel-gasoline blends for a multi-hole injector with asymmetrical nozzle-hole arrangement by means of high-speed shadow photography technique. This is favorable to applying biofuel-gasoline to homogeneous charge compression ignition combustion operation, contributing to the improvement in compression ignition ability. The spray characteristics such as the spray tip penetration spray cone angle spray tip speed and spray projection area were analyzed in an optical chamber, employing biofuel-gasoline blends of pure gasoline-B0, 10\% biofuel-B10, 20\% biofuel-B20 and 30\% biofuel-B30. This work is believed to be meaningful to direct injection homogeneous charge combustion ignition (DI-HCCI) engines; the addition of biofuel is more favorable to improving compression ignition ability and high-pressure pump friction.

\section{Experimental setup and conditions}

\section{Spray visualization experimental test rig}

The experimental setup is depicted in Fig.1, which is composed of a constant volume chamber, a fuel-supplying system, the DISI injector with six nozzle holes and $57^{\circ}$ nozzle hole-hole angle shown in Figure 2, and a high-speed CCD used for photographing the spray history. The constant volume chamber can be pressurized up to $5 \mathrm{MPa}$ with $\mathrm{N} 2$ gas. The fuel was supplied under constant pressure from an accumulator pressurized with $\mathrm{N} 2$ gas.

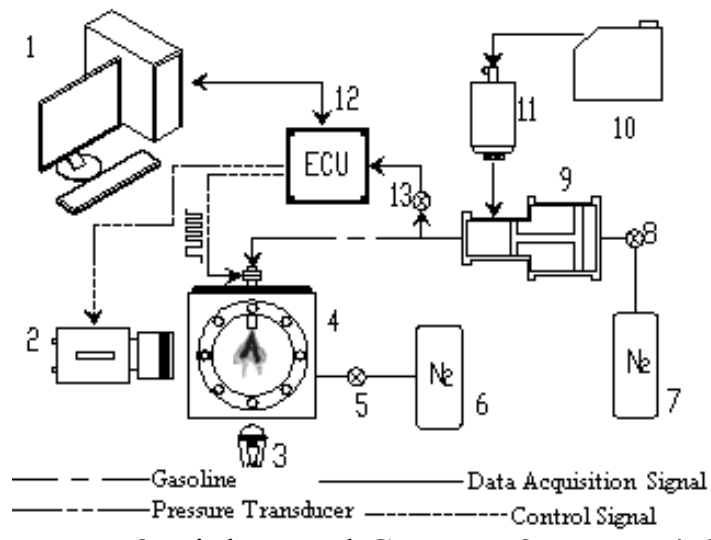

1 Computer, 2 High-speed Camera, 3 Lamp, 4 Optical Chamber, 5,8 Gas Pressure Meter, 6,7 Nitrogen Tank, 9 Fuel Supply System, 10 Gasoline Tank, 11 Gasoline Filter, 12 ECU, 13 Oil-pressure Transducer

Fig. 1 Spray experimental

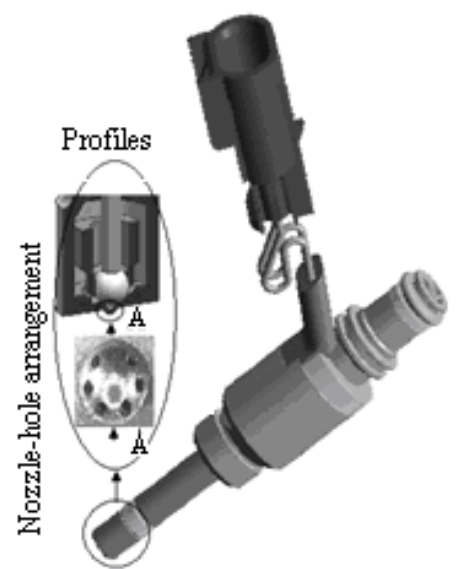

Fig.2 Scheme of the nozzle structure 
The spray characteristics such as the spray tip penetration, spray cone angle, sprays tip speed and spray projection area were calculated using self-programming software. In addition, the frame rate of the high speed camera was maintained at 25,000 fps. The specifications of the high speed camera and the GDI injector are shown in Table 1.

Table.1 Specifications of high speed camera and GDI injector

\begin{tabular}{|cll|}
\hline Apparatus & Parameters & Values \\
High-speed & Sample rate & $25000 \mathrm{fps}$ \\
camera & Resolution & $320 \times 320$ \\
& Exposure time & $20 \mathrm{us}$ \\
& Peak working pressure & $15 \mathrm{MPa}$ \\
& Static mass flow & $10 \mathrm{~g} / \mathrm{s} @ 10 \mathrm{MPa}$ \\
GDI injector & Nozzle hole dameter & $0.179 \mathrm{~mm}$ \\
& Nozzle hole number & 6 \\
\hline
\end{tabular}

\section{Experimental conditions and parameter definition}

To clarify the effect of biofuel fraction on the spray properties, the experiments have been carried out with pure gasoline (B0) and several different biofuel-gasoline blends (B10, B20 and B30), in which the number indicates the biofuel volume percentages. The spray injected into low ambient pressure $(0.1 \mathrm{MPa})$ condition simulated the early injection mode in GDI engine under high load condition. While the sprays injected into the elevated ambient pressure $(0.6 \mathrm{MPa})$ condition represented the late fuel injection modes for stratified charge combustion operation. The detailed experimental conditions are listed in Table 2.

Table.2 Experimental conditions

\begin{tabular}{|ll|}
\hline Parameters & Values \\
Injection pressure(MPa) & $3,6,9,12$ \\
Ambient pressure(MPa) & $0.1,0.6$ \\
Ambient temperature $(\mathrm{K})$ & 293 \\
Blended ratio & $0 \%, 10 \%, 20 \%, 30 \%$ \\
\hline
\end{tabular}

In the study, the spray characteristics such as the spray tip penetration and spray cone angle were calculated using self-programming software. By specifying a spray image threshold, the edge of the spray plume could be determined from the images. The spray tip penetration was defined as the distance from the injector nozzle tip to the spray tip. The spray cone angle was obtained by measuring the angle between the outer edges of the spray, as shown in Fig. 3.

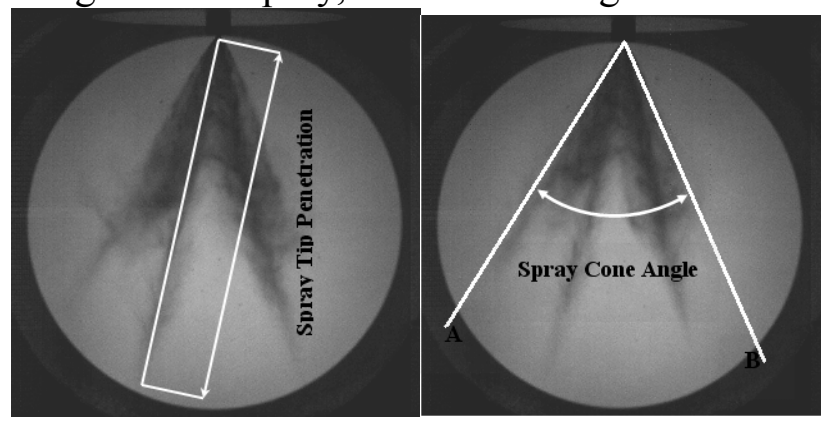
(a)spray tip penetration
(b) spray cone angle

Fig. 3 Definition of spray parameters

The spray tip speed was defined as follows.

$v=\left(L_{i}-L_{i-1}\right) / \nabla t$

Where $v$ is the spray tip speed $(\mathrm{m} / \mathrm{s})$,

$L_{i}$ is the spray tip penetration of $i$ image $(\mathrm{mm})$,

$\nabla t$ is the time interval $(\mathrm{ms})$. 
The spray projection area was defined as one of spray outer profile projected on the axis cross-section of the injector.

\section{Post-processing procedures of spray images}

Some routine image processing softwares such as Photoshop can't be directly used for calculating the spray tip penetration, spray cone angle, etc. Therefore, the spray image-processing software is made by means of Matlab procedures. The spray images are processed by means of a lot of methods including the image conversion, the threshold value segmentation, the edge detection and the target recognition etc. The special histories flowchart and software interface are shown in Fig.4 and Fig.5.

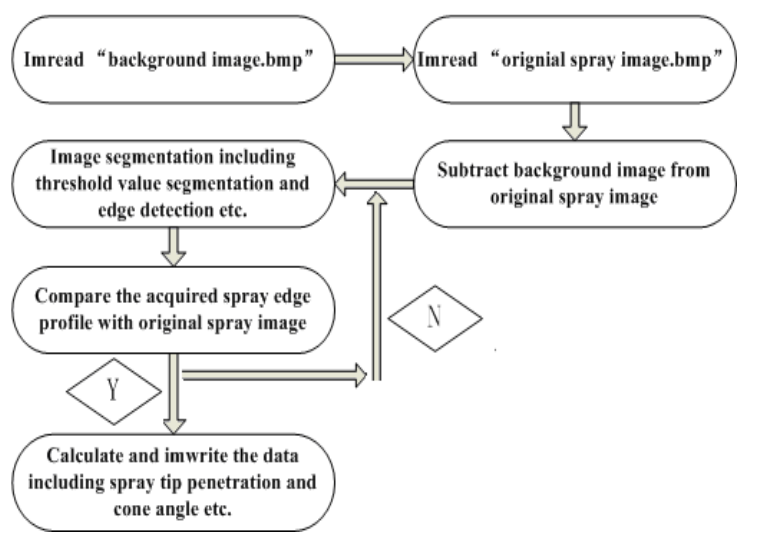

Fig. 4 Spray image post-process flowcharts image-processing software interface

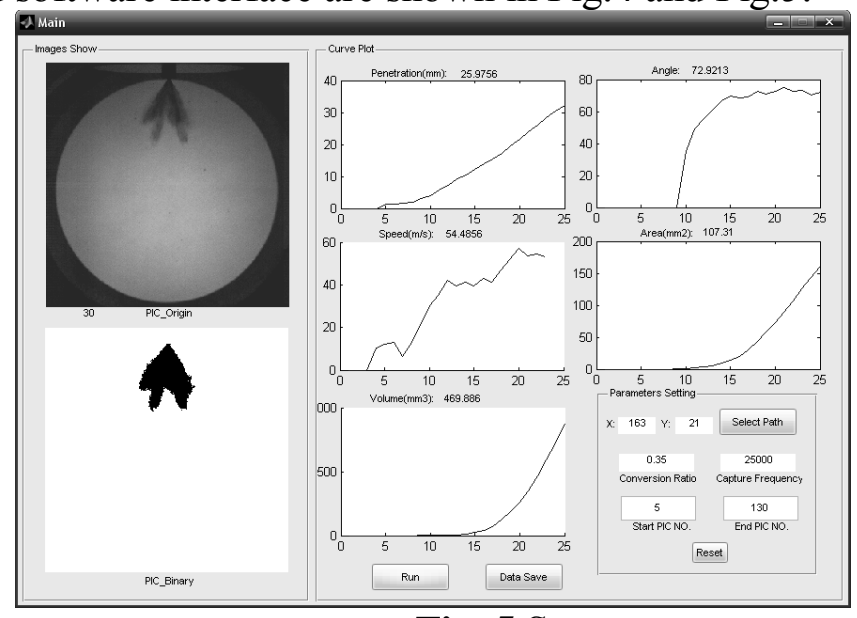

Fig. 5 Spray

The post-processing spray images by means of self-compiling procedures are shown in Fig. 6 .

Fig. 6 presents the original and post-processing gasoline spray histories under injection pressure $9 \mathrm{MPa}$, ambient pressure $0.1 \mathrm{MPa}, 0.6 \mathrm{MPa}$ and ambient temperature $25 \mathrm{oC}$ conditions. Comparing the original with post-processing images, it can be concluded that the calculating results by self-programming software are reasonable and correct.

$\begin{array}{lllll}P_{a m b} & 1 \mathrm{~ms} & 2 \mathrm{~ms} & P_{a m b} & 1 \mathrm{~ms}\end{array}$

0.1

MP

a

Pro

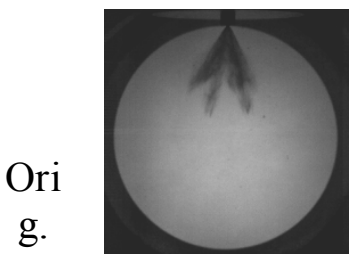

g.

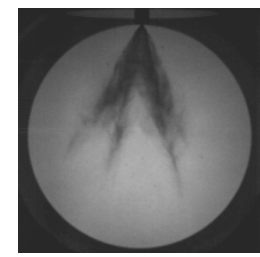

0.6

MP

a
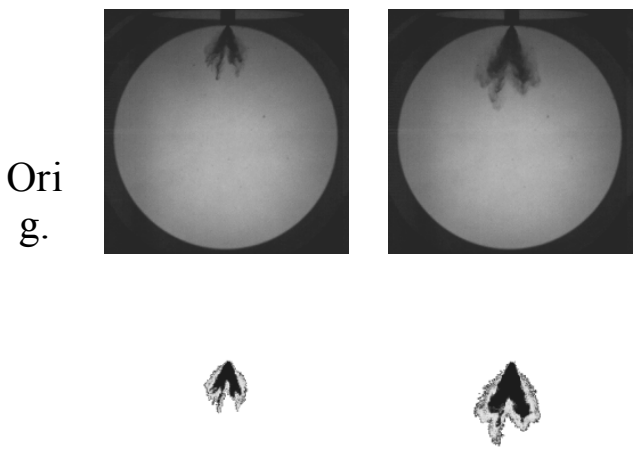

Pro

Fig. 6 Comparison between original and post-processing spray configureuration with gasoline

\section{Results and discussion}

The spray characteristics are known to be critical to the process of vaporization, mixing and combustion stability. Therefore, the spray concentration, spray tip penetration, spray cone angle, spray tip speed and spray projection area were calculated with the aid of a program made by the 
authors. In addition, the start of injection was determined based on the moment that the spray leaves the injector nozzle, excluding the mechanical opening delay and driver electronic delay. In the experiment, the testing biofuel was made from edible waste oil, and the blends were also made on site by volume ratio.

\section{Spray histories}

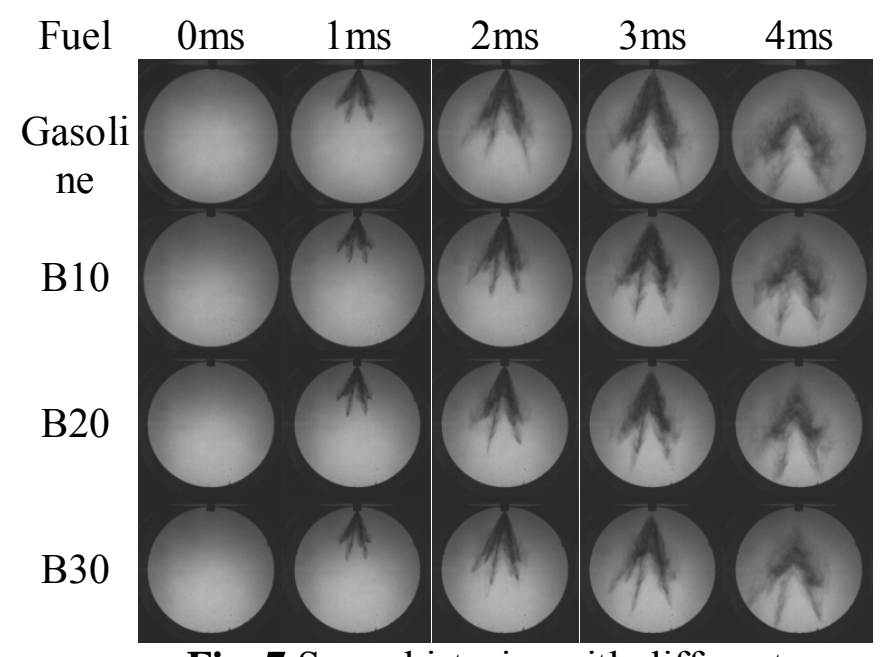

Fig. 7 Spray histories with different gasoline-biofuel blends under injection pressure $9 \mathrm{MPa}$, ambient pressure $0.1 \mathrm{Mpa}$ and ambient temperature $25^{\circ} \mathrm{C}$

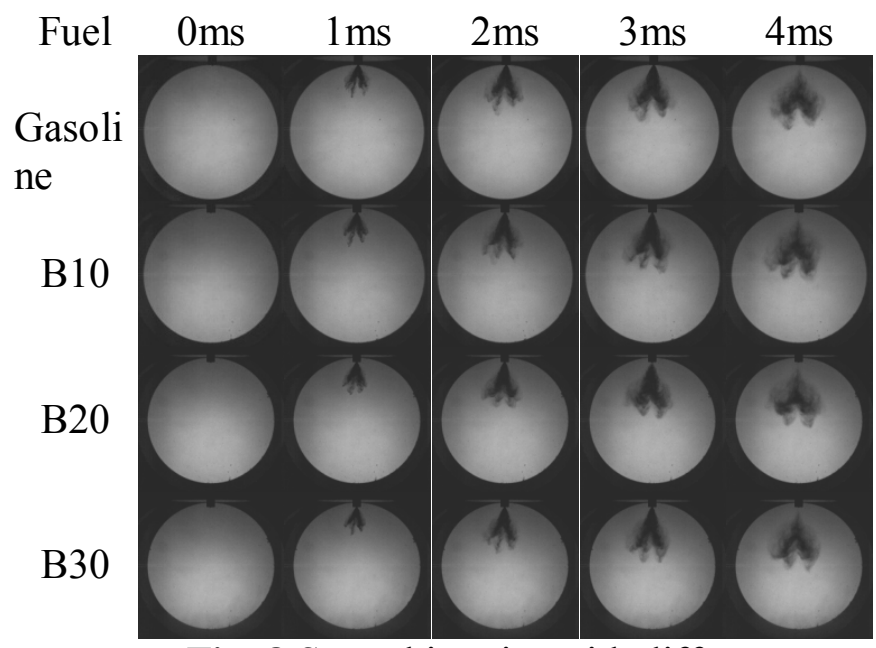

Fig. 8 Spray histories with different gasoline-biofuel blends under injection pressure $9 \mathrm{MPa}$, ambient pressure $0.6 \mathrm{MPa}$ and ambient temperature $25^{\circ} \mathrm{C}$ 


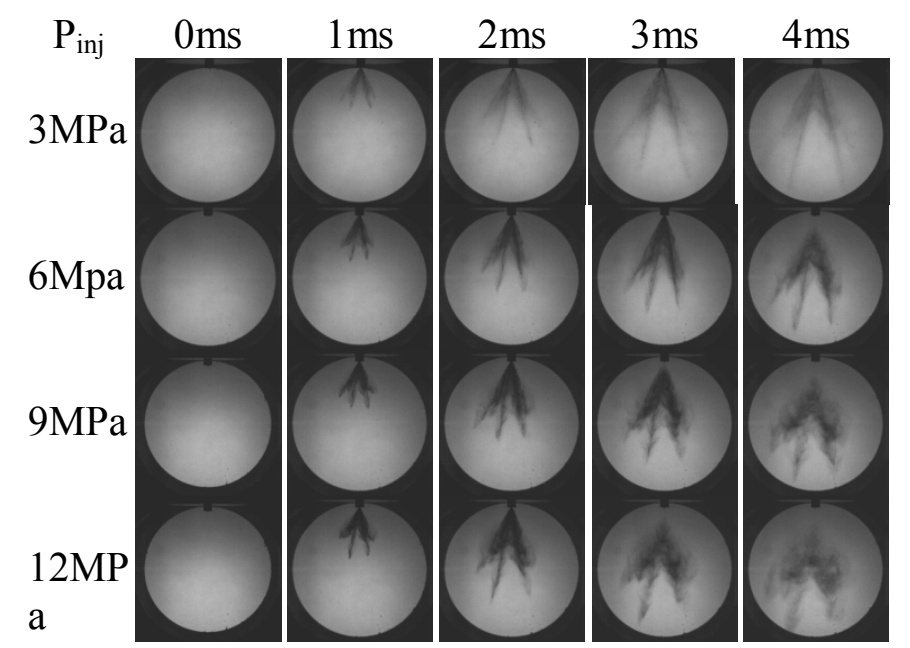

Fig. 9 Spray histories with B10 blends under injection pressure $6,9,12 \mathrm{MPa}$, ambient pressure

$0.1 \mathrm{MPa}$ and ambient temperature $25^{\circ} \mathrm{C}$

The spray histories with different gasoline-biofuel blends under injection pressure 9MPa, ambient pressure $0.1 \mathrm{MPa}, 0.6 \mathrm{MPa}$ and ambient temperature $25^{\circ} \mathrm{C}$ conditions, are shown in Fig. 7 and Fig. 8, respectively. It can be seen that, in the case of low ambient pressure, the amount of fuel injection tended to be reduced, and the spray atomization degraded with increasing biofuel volume fraction in the gasoline. In addition, the spray tip penetration and spray cone angle increased and decreased with increasing biofuel volume fraction in the gasoline, due mainly to the fact that an increase in the biofuel volume fraction in the gasoline results in the increase in the viscosity and surface tension of the blended fuels.

Under elevated ambient pressure condition, the difference of the spray shape seemed to be distinct with increasing blend ratio of biofuel in the gasoline, but the discrepancy gradually decreased as time elapsed, this is possibly due to the fact that the increase in the ambient pressure results in the increase in the N2 density; further, the effect of the stronger ambient resistance on the spray development conceals the influence of the increase in the viscosity and surface tension.

Fig.9 shows the spray histories with B10 blends under injection pressure 6, 9, 12MPa, ambient pressure $0.1 \mathrm{MPa}$ and ambient temperature $25 \mathrm{oC}$ conditions. It can be seen that the amount of fuel injection seemed to increase with increasing the injection pressure. And the spray tip penetration increased as well, due to an increase in the injection pressure resulting in initial velocity improvement. In addition, the tendency is the same with one of the gasoline spray histories.

\section{Spray characteristics with different blend ratios}

Fig. 10 shows the spray tip penetrations for pure gasoline and the blends with different biofuel volume fractions under injection pressure $9 \mathrm{MPa}$, ambient pressure $0.1 \mathrm{MPa}$ and ambient temperature $25 \mathrm{oC}$ condition. It can be seen that the spray tip penetration increased with increasing biofuel volume fraction in the gasoline. This mainly is because an increase in fuel viscosity prevents the breakup of the spray jet, resulting in an increase in the size of the spray droplets. The larger the size of the spray droplets, the higher their momentum and the smaller the resistance preventing forward movement. The increase in the spray tip penetration is little favorable to decreasing spray-wall impingement events. Therefore, the fuel injection during the intake stroke should be postponed for direct injection (DI) engines. It can be also seen that the spray tip penetration with pure gasoline is about $7 \mathrm{~mm}$ smaller than that with the blends of B30 when the spray tip penetration tended to keep constant.

In addition, the increasing rate in the spray tip penetration substantially decreased after the time of $3 \mathrm{~ms}$, but that of the blends were postponed until $3.5 \mathrm{~ms}$.

Fig. 11 shows the spray cone angles for pure gasoline and the blends with different biofuel volume fractions under injection pressure $9 \mathrm{MPa}$, ambient pressure $0.1 \mathrm{MPa}$ and ambient temperature $25 \mathrm{oC}$ condition. It can be seen that the spray cone angle decreased with increasing biofuel volume fraction in the gasoline; this mainly is because an increase in the viscosity and surface tension results in larger spray droplets and the reduction in spray cloud diffusion. In addition, the larger droplets have the 
higher momentum along the nozzle-hole-axis direction. Therefore, the spray clouds tended to move forward, and reduced the spray spread towards the radial direction of the nozzle. In addition, the spray cone angle with gasoline is averagely close to 3.50 larger than that with the blends of B30 as time elapsed.

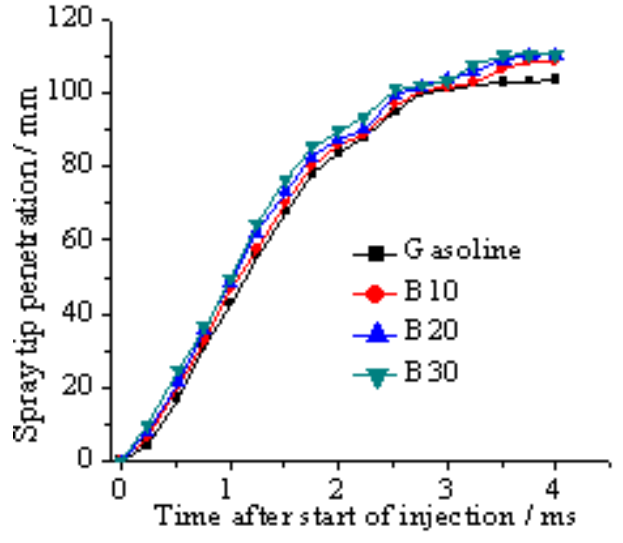

Fig.10 Spray tip penetrations with different blend ratios under injection pressure $9 \mathrm{MPa}$, ambient pressure $0.1 \mathrm{Mpa}$ and ambient temperature $25^{\circ} \mathrm{C}$

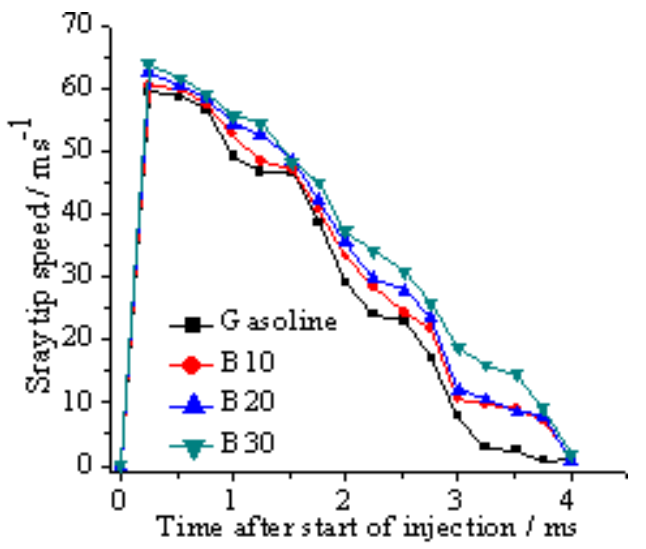

Fig.12 Spray tip speeds with different blend ratios under injection pressure $9 \mathrm{MPa}$, ambient pressure $0.1 \mathrm{MPa}$ and ambient temperature $25^{\circ} \mathrm{C}$

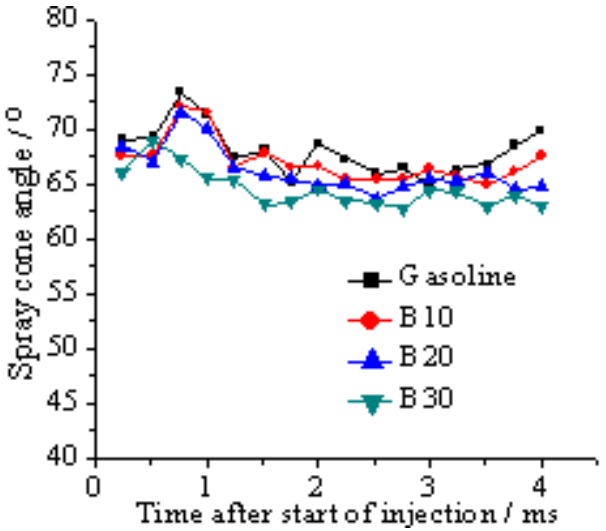

Fig.11 Spray cone angles with different blend ratios under injection pressure $9 \mathrm{MPa}$, ambient pressure $0.1 \mathrm{MPa}$ and ambient temperature $25^{\circ} \mathrm{C}$

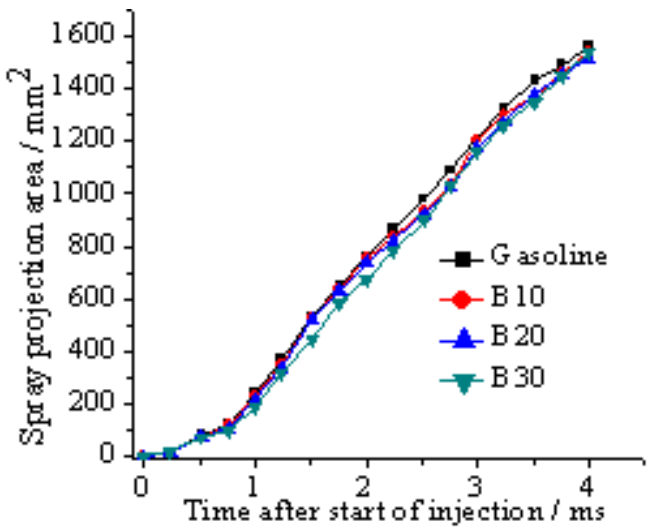

Fig.13 Spray projection areas with different blend ratios under injection pressure $9 \mathrm{MPa}$, ambient pressure $0.1 \mathrm{MPa}$ and ambient temperature $25^{\circ} \mathrm{C}$

Fig.12 shows the spray tip speeds for pure gasoline and three blends under injection pressure $9 \mathrm{MPa}$, ambient pressure $0.1 \mathrm{MPa}$ and ambient temperature $25 \mathrm{oC}$ condition. It can be seen that the spray tip speed increased with increasing biofuel volume fraction in the gasoline; this is because an increase in the viscosity and surface tension results in larger spray droplets. Further, an increase in fuel viscosity prevents the breakup of the spray jet, and results in an increase in the size of the spray droplets. The larger the size of the spray droplets, the higher their momentum and the smaller the resistance preventing forward movement. At the later period of spray histories, the spray tip speed with pure gasoline decreased faster. This is due to faster vaporization and atomization of pure gasoline.

Fig. 13 shows the spray projection areas for pure gasoline and three different blends under injection pressure $9 \mathrm{MPa}$, ambient pressure $0.1 \mathrm{MPa}$ and ambient temperature $25 \mathrm{oC}$ condition. It can be seen that the spray area projection tended to become small with increasing biofuel volume fraction in the gasoline. And as time elapsed, the tendency was more obvious, due to the fact that the smaller size of the droplets with pure gasoline results in the faster diffusion.

\section{Spray concentrations of the blends with different blended ratios}

The spray fuel concentration with various blend ratios of biofuel in the gasoline under three cases (injection pressure $9 \mathrm{MPa}$, ambient pressure $0.1,0.6 \mathrm{MPa}$, ambient temperature $25^{\circ} \mathrm{C}$; injection 
pressure $6 \mathrm{MPa}$, ambient pressure $0.1 \mathrm{MPa}$, ambient temperature $25^{\circ} \mathrm{C}$ ), were investigated employing some spray images and the spray post-processing software. The details are introduced in Fig.14, Fig.15 and Fig.16.

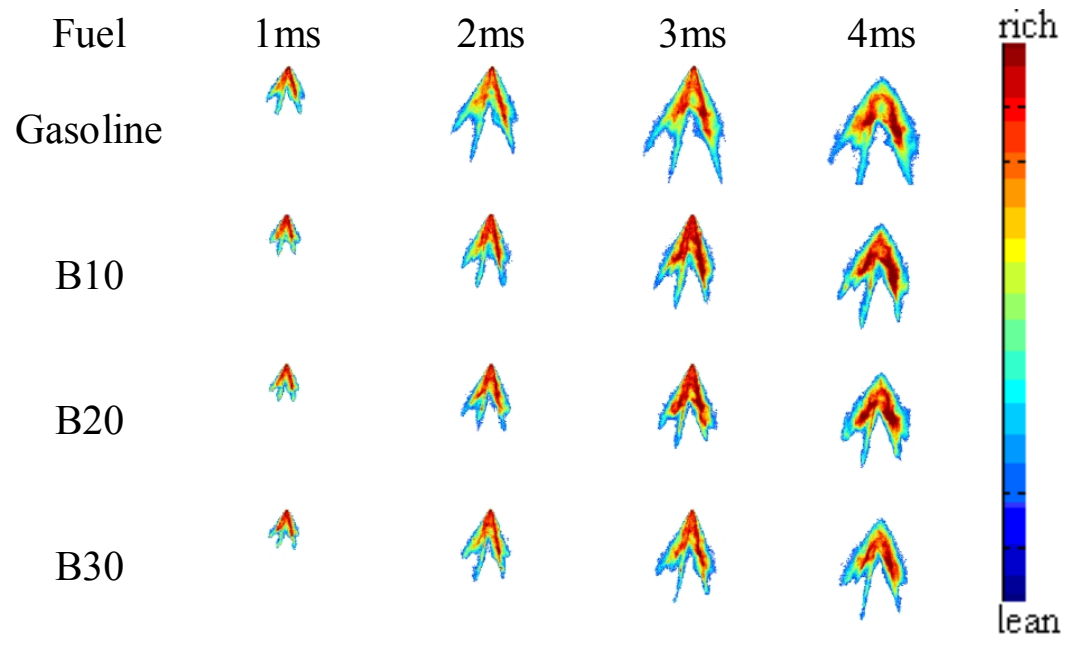

Fig.14 Spray concentrations of the blends with different blend ratios under injection pressure $6 \mathrm{MPa}$, ambient pressure $0.1 \mathrm{MPa}$ and ambient temperature $25^{\circ} \mathrm{C}$

Fig. 14 shows the spray fuel concentration of the blends with different biofuel volume fraction in the gasoline under injection pressure $6 \mathrm{MPa}$, ambient pressure $0.1 \mathrm{MPa}$ and ambient temperature $25 \mathrm{oC}$ condition. It can be seen that fuel atomization degraded with the increase in biofuel volume fraction in the gasoline, this is due to the fact that the fuel viscosity and surface tension are increased. In addition, when the biofuel volume fraction added up to $30 \%$, the spray fuel concentration seemed to become lean once again, due possibly to the fact that the increase in the biofuel volume fraction results in fuel injection amount reduction.

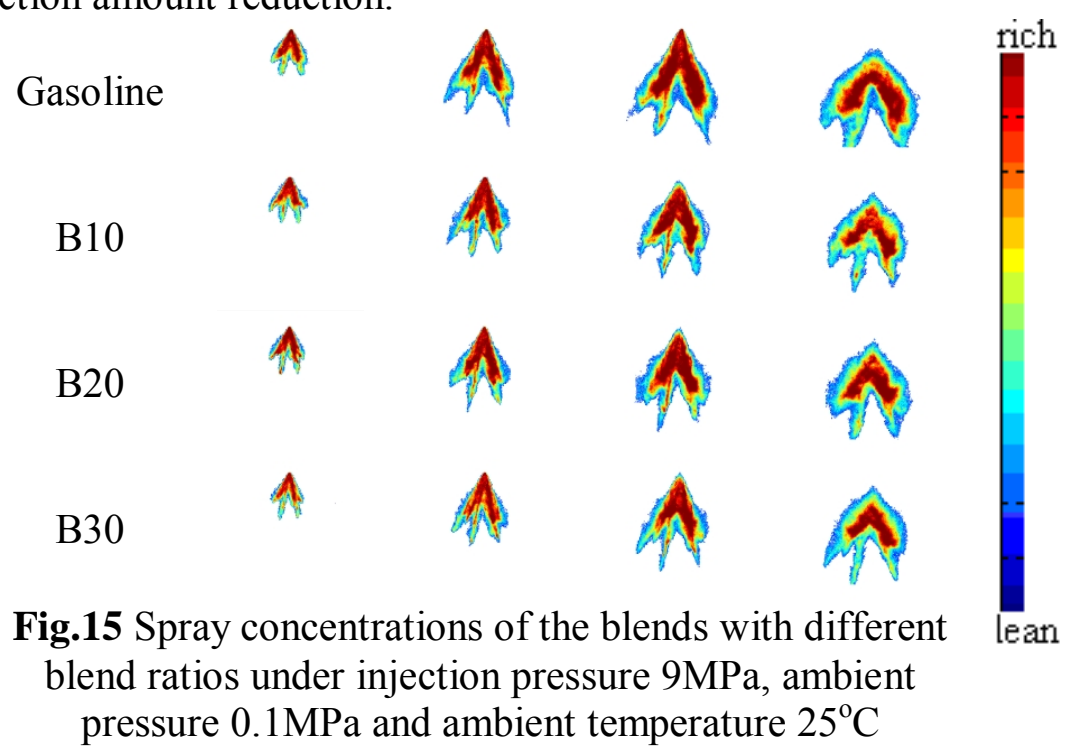

Fig. 15 shows the spray fuel concentrations of the blends with different biofuel volume fraction in the gasoline under injection pressure $9 \mathrm{MPa}$, ambient pressure $0.1 \mathrm{MPa}$ and ambient temperature $25 \mathrm{oC}$ condition. It can be seen that the spray fuel concentration around the spray clouds became leaner and leaner with the increase in biofuel volume fraction in the gasoline, resulting mainly from that the increase in biofuel contents induces the increase in fuel viscosity and surface tension, further the amount of the fuel injection is reduced. 


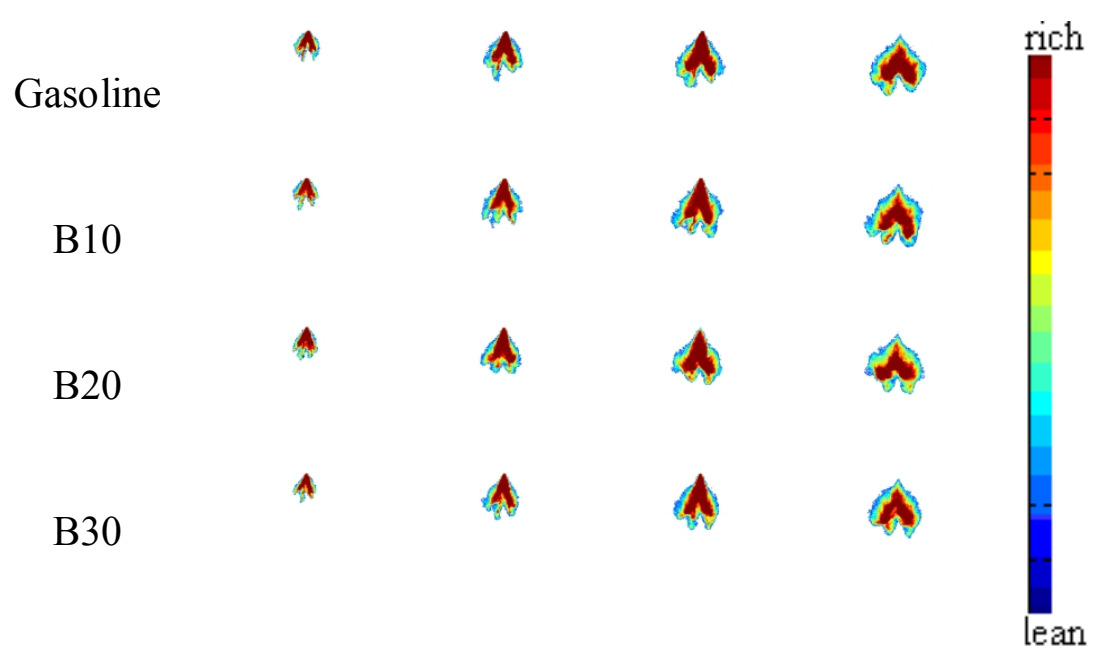

Fig.16 Spray concentrations of the blends with different blend ratios under injection pressure $9 \mathrm{MPa}$, ambient pressure $0.6 \mathrm{MPa}$ and ambient temperature $25^{\circ} \mathrm{C}$

Fig.16 shows the spray fuel concentration of the blends with different biofuel volume fraction in the gasoline under injection pressure $9 \mathrm{MPa}$, ambient pressure $0.6 \mathrm{MPa}$ and ambient temperature $25 \mathrm{oC}$ condition. It can be seen that the fuel concentration around the spray clouds was close to each other, because the bigger density of ambient charge decreases spray diffusion and atomization.

Comparing the results in Fig. 14 and Fig. 15, the spray fuel concentration was richer and richer with increasing the injection pressure, regardless of the blend ratios. It is due to the fact that improving the injection pressure results in an increase in the fuel injection rate.

Comparing the results in Fig.15 and Fig.16, the spray fuel concentration was richer and richer with increasing the ambient pressure, regardless of the blend ratio. It is due possible to the fact that an increase in ambient pressure brings high ambient density and a large drop drag force, thus the fuel evaporation degrades.

\section{Conclusions}

(I)The influence of blend ratio of biofuel in the gasoline on the spray patterns became more prominent under low ambient pressure condition than that under high ambient pressure condition. In addition, the spray pattern tended to become similar to each other under high ambient pressure condition as time elapsed.

(II)With increasing blend ratios of biofuel in the gasoline, the spray tip penetration and the spray tip speed increased; but the spray cone angle and the spray projection decreased. In addition, the spray tip penetration with pure gasoline is about $7 \mathrm{~mm}$ shorter than that with the blends of B30 when the spray tip penetration tended to keep constant, while the spray cone angles with gasoline is averagely close to $3.5^{\circ}$ larger than that with the blends of B30 as time elapsed.

(III)The spray concentration of the fuel with various blend ratios tended to become similar with increasing ambient pressure. In addition, regardless of the blend ratio, the spray fuel concentration was richer and richer with increasing the injection pressure, due to the increase in fuel injection rate. (IV)The spray atomization was slightly degraded when the blend ratio of biofuel in the gasoline by volume was under $30 \%$, due mainly to an increase in the viscosity of the blends. In addition, the fuel injection rate was The influence of blend ratio of biofuel in the gasoline on the spray patterns became more prominent under low ambient pressure condition than that under high ambient pressure condition. In addition, the spray pattern tended to become similar to each other under high ambient pressure condition as time elapsed.

\section{Acknowledgements}

The authors would like to appreciate the funding of this study from shanghai production and project. 


\section{References}

[1] Zhao F Q, Harrington D L, Lai M C. submitted to Society of Automobile Engineers Inc.2002.

[2] Gao J, Jiang D M, Huang Z H. submitted to Fuel, 2007, 86:1645-1650.

[3] Zhang X S, Li L G, Deng J, et al. submitted to Transactions of CSICE, 2007, 25:172-176.

[4] Shiraishi T, Nakayama Y, Nogi T. submitted to SAE Paper 980156, 1998.

[5] Lee K H., Lee C H, Lee C S. submitted to Fuel, 2004, 83: 917-980.

[6] Keiya N, Tian J P, Yasuki S., submitted to Fuel, 2009, 88: 1634-1642.

[7]Aleiferis P G., Serras P J, Van R Z. et al, submitted to,Combustion and Flame. 2010, 157: 735-756 